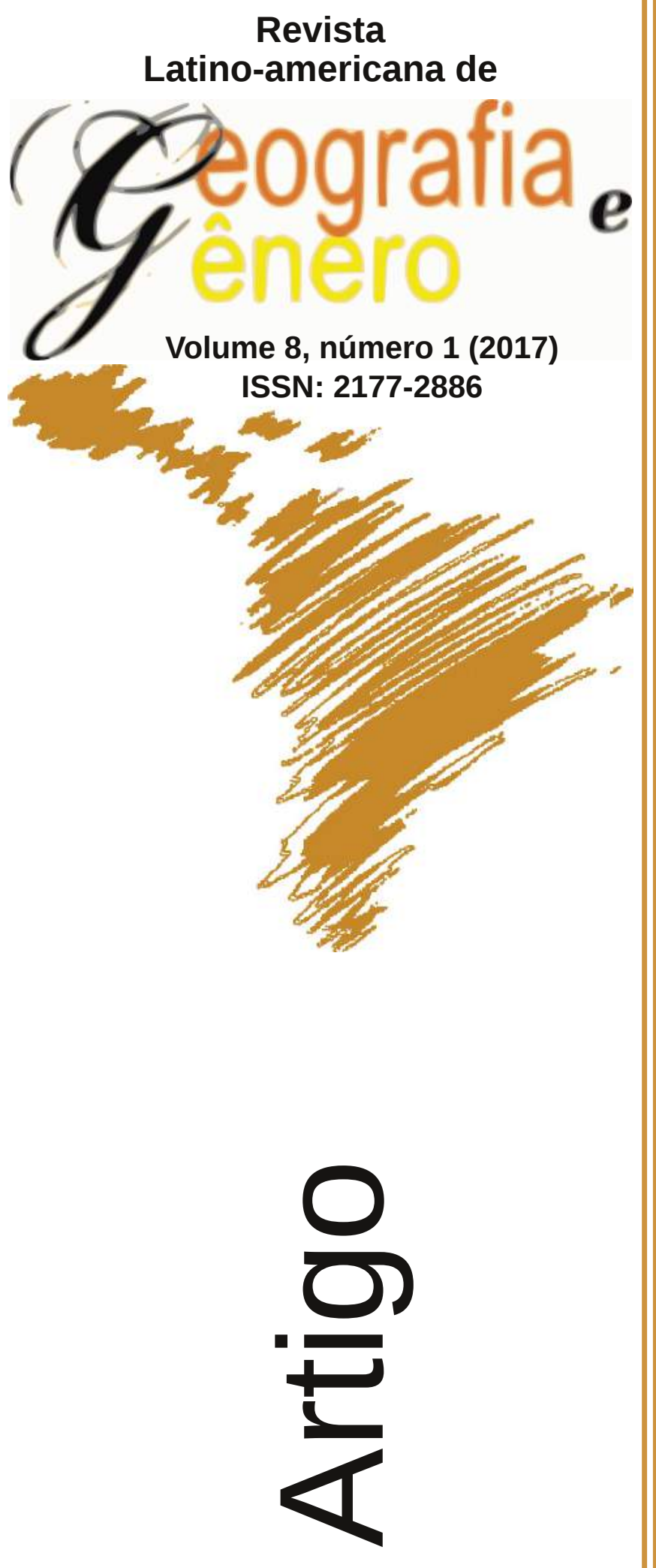

\section{Gênero e Corporeidadle}

Género y Corporalidad

Gender and Corporeality

\author{
Roseli Alves Santos \\ Universidade Estadual do Oeste do Paraná - \\ Brasil \\ roseliasantos@gmail.com \\ Cleusa Regina Ferreira da Luz \\ Universidade Estadual do Oeste do Paraná - \\ Brasil \\ luizcts@gmail.com
}

Como citar este artigo:

SANTOS, Roseli Alves; SANTOS, Luiz César Teixeira dos. Gênero e Corporeidade. Revista Latino Americana de Geografia e Gênero, v. 8, n. 1, p. 177 193, 2017. ISSN 2177-2886.
Disponível em:

http://www.revistas2.uepg.br/index.php/rlagg 


\title{
Gênero e Corporeidade
}

\author{
Género y Corporalidad
}

Gender and Corporeality

\section{Resumo}

Este texto é resultado de um trabalho desenvolvido entre profissionais da Geografia e da Educação Física, no qual se discute a questão da mulher na sociedade contemporânea e as implicações oriundas da conformação do conceito de gênero em nossa sociedade. Foram considerados, para essa pesquisa, as experiências vivenciadas durante oficinas realizadas com grupos constituídos por educadoras e educadores da educação básica do município de Francisco Beltrão e de Palmas, em que se debateu sobre a temática de gênero, tendo como eixo orientador. Os relatos das educadores e educadores participantes demonstram a existência de comportamentos, atitudes e falas que reforçam preconceitos historicamente presentes na sociedade brasileira, independentemente de gênero. Assim, no presente texto, busca-se refletir e questionar modelos determinados pela cultura dominante como parâmetros do que deva ser o homem e a mulher, de como devem ser educados e de como precisam se comportar.

Palavras-Chave: Gênero; Corporeidade; Escola.

\section{Resumen}

Este texto es el resultado del trabajo desarrollado entre profesionales de la geografía y de la educación física, en el que se discute la cuestión de la mujer en la sociedad contemporánea y las implicaciones de la conformación del concepto de género en nuestra sociedad. Para este estudio se tuvieron en cuenta las experiencias vividas durante talleres realizados con grupos formados por educadoras y educadores de educación básica en el municipio de Francisco Beltrão y de Palmas, en los que se discutieron cuestiones de género. Los informes de las educadoras y educadores participantes demuestran la existencia de comportamientos, actitudes y discursos que refuerzan los prejuicios históricamente presentes en la sociedad brasileña, independientemente del sexo. Así, en este texto, se pretende reflexionar y cuestionar los modelos determinados por la cultura dominante como parámetros de lo que deberían ser los hombres y las mujeres, la forma en que deben ser educados y cómo tienen que comportarse.

Palabras-Clave: Género; Corporalidad; Escuela.

\begin{abstract}
This text is the result of a work conducted among professionals of geography and physical education, which discusses the question of women in contemporary society and the implications from the conformation of the concept of gender in our society. In this research, it were considered experiences occurred during workshops with groups of female and male educators who teach in basic education in the towns of Francisco Beltrão and Palmas, which discussed the theme of gender. The reports of the educators demonstrated the existence of behaviours, attitudes and statements that reinforce prejudices historically present in Brazilian society, regardless of gender. This text aims to reflect and question models determined by the dominant culture as the parameters of how should be the man and the woman, how to be polite and how they must behave.
\end{abstract}

Keywords: Gender; Body; School. 
Introdução

As análises contidas neste artigo se pautam por uma temática multidisciplinar e a construção deste texto resulta da experiência vivenciada, através de um projeto de extensão universitária, entre uma professora de Geografia e um professor de Educação Física que propuseram um debate, em formato de oficinas, com 60 educadores e educadoras da rede de ensino da educação básica na região sudoeste do Paraná, nos anos de 2013, 2014 e 2015, nos municípios de Francisco Beltrão e de Palmas. Também corrobora para esta reflexão as experiências colhidas durante o $1^{\circ}$ e $2^{\circ}$ Ciclos de Debates: Mulher na Sociedade Contemporânea, que a partir da contribuição de ativistas, professores, profissionais liberais e pesquisadores, trataram de temáticas como: saúde do homem; violência contra mulher; educação, gênero e etnia; homoafetividade; mulheres e trabalho; organização política; entre outros. Ademais, contribui para as reflexões presentes neste texto o debate efetivado no I e II Seminário Latino Americano de Gênero e Geografia, realizado em 2010 e 2014 e a participação na $9^{\mathrm{a}}$ e $10^{\mathrm{a}}$ edição do Seminário Internacional Fazendo Gênero. Essas reflexões e estudos possibilitaram a ampliação do debate e da compreensão da temática de gênero pelos professores integrantes da Universidade e por acadêmicos dos cursos de licenciatura que participaram da realização dos projetos.

A metodologia utilizada consistiu da integração entre a pesquisa bibliográfica e as atividades empíricas realizadas no formato de oficinas. As experiências vivenciadas, junto aos grupos de educadores e de educadoras, partiram do pressuposto que o corpo é uma marca, que faz parte da construção da identidade de homens e mulheres. Nesta construção, a forma como lidamos com a leitura corporal do ser homem e do ser mulher, especialmente no cotidiano da sala de aula, constitui-se em um elemento que é marcado pela cultura e se efetiva como uma construção material e imaterial de uma sociedade. O corpo é efetivamente uma forma de expressão e se constitui em um meio com o qual dialogamos com a sociedade.

Cada história de vida é uma história de um corpo e cada corpo tem um sexo que possui valor histórico, social e cultural. O conceito de corpo diz respeito aos significados e sentidos que podemos atribuir a qualquer interação que se estabelece (consigo mesmo, com os outros ou com objetos), ou seja, o corpo é o organismo atravessado por todas as experiências vividas, pela inteligência e pelo desejo (JOFFLY, 2010, p. 226).

É neste sentido que trabalhar a temática de gênero e corporeidade, com professores e professoras da rede básica do ensino, nos parece uma questão fundamental, uma vez que a educação inclui, também, uma educação corporal. Logo, é imprescindível que os educadores e educadoras tenham consciência de sua ação educativa ao trabalhar com os/as estudantes, não só de sua ação educativa, no sentido de uma matriz teórico-conceitual voltada para a apreensão cognitiva, mas também e fundamentalmente de sua ação educativa 
sobre a corporeidade daqueles que vivem o cotidiano educacional.

Este texto está organizado em duas partes, uma primeira onde discutimos questões sobre gênero e corpo, e outra em que abordamos, a partir de uma experiência prática com educadores, como a escola influencia nas concepções de gênero e corporeidade e quais implicações podem decorrer do modo como a educação lida com estes elementos.

\section{Gênero e Corpo: Algumas Considerações}

Como nosso foco de debate é o processo educativo sobre gênero e corporeidade, não podemos nos furtar a apontar algumas formas concretas em que se apreende a ser homem e a ser mulher na sociedade patriarcal e na qual a participação da escola é indubitável.

Antes do nascimento de uma criança, a sociedade já define qual será a sua cor. Não a cor da pele, mas as cores que remetem, equivocadamente, à identidade de gênero: rosa ou azul. Para os menos radicais: amarelo ou verde água. Assim, a criança já chega ao mundo com um preconceito à ela instituído e, ao longo de sua vida, este é reforçado nos brinquedos e brincadeiras que reproduzem o que se espera para o futuro das meninas e meninos.

A própria maternidade, que supostamente encerra em si uma questão natural, reforça o papel socialmente definido para a mulher, desde a escolha do enxoval do bebê e a organização de como cuidará ou delegará à outra pessoa (geralmente uma mulher) o cuidar do bebê, independente de ter ou não um(a) companheiro(a). A maternidade está vinculada à figura da mulher e não estamos nos referindo ao gerar, mas ao criar o filho/a. Embora pareça ser absolutamente natural a identificação de determinados comportamentos ou instintos à maternidade, por um lado, e a vinculação à comportamentos mais virilizados estarem relacionados mais à figura masculina, por outro, consideramos urgente repensar estas verdades e indagarmos se de fato são comportamentos oriundos de uma matriz biológica, vinculados intimamente ao desenvolvimento da espécie ou se são construções fortemente marcadas por aspectos culturais, por interesses sócio históricos e comprometidos com a manutenção de um determinado status quo patriarcal ainda imperativo na atualidade.

O modo dominante de viver e construir a identidade de gênero é fortemente reforçado pelas instituições modernas e, nesse sentido, podemos observar os estereótipos de gênero no discurso e na prática política, religiosa, nos clubes sociais de lazer e entretenimento, na lógica de mercado e produção, na indústria de brinquedos, na produção midiática entre outros. Ademais, nos interessa aqui a reflexão sobre a reprodução estereotipada de gênero que a escola contribui para disseminar. Nesse sentido, é importante que a educação experimente revisitar seus valores, rever seus jargões, repensar de modo crítico os discursos e realinhar a prática pedagógica relativa à esta temática e as ações cotidianas nas instituições educacionais, desde a educação infantil ao ensino superior.

Falar de gênero implica, incontestavelmente, transitar pelas discussões sobre corporeidade. E ao debruçarmos sobre esta, entramos em um terreno movediço. Não que o corpo seja algo por demais complicado, ao menos não

Roseli Alves Santos, Luiz César Teixeira dos Santos 
deveria ser. No entanto, como afirma Gaiarsa (1986), a sociedade fala muito sobre o corpo, mas, na prática, não apenas o maltrata como luta por escondêlo. A civilização ocidental contribuiu bastante para formarmos muitas ideias descabidas sobre o que é e como é o nosso corpo. Como exemplo disto, crescemos com inúmeros preconceitos em relação ao sexo e à sexualidade, ao como devemos andar, sentar, nos expressar diante das outras pessoas ou reagir frente às situações cotidianas. A educação informal, tanto quanto a educação escolar, reforça que os corpos devem assumir comportamentos distintos e, quase sempre, não sabemos o porquê de tais atitudes nem, tampouco, por que tem que ser ou se tem que ser, necessariamente, daquela forma.

Normalmente, os meninos aprendem que o homem precisa ter determinadas características e expressões, transitando por um tipo mais rústico e embrutecido, que não deve demonstar muita delicadeza. Homem tem que se cuidar, se arrumar, mas não muito, porque não 'pega bem'. Ao andar, é interessante que os movimentos sejam soltos e descontraídos, mas o código da corporeidade masculina reza que o caminhar deve ser firme.

Para o corpo feminino, as coisas caminham um pouco diferente. As meninas são educadas por um estereótipo para o qual a delicadeza é parte integrante do gênero feminino. $\mathrm{O}$ andar solto e descontraído também é bem-vindo, e se tiver suavidade e balanço tanto quanto melhor; a firmeza se restringe ao meramente necessário para manter-se ereto.

Estes são apenas alguns exemplos da maneira como está alicerçada a representação social sobre a corporeidade. Entretanto, não queremos dizer que somos todos iguais, muito pelo contrário, como mostra Gaiarsa (1986), somos infinitamente múltiplos, tanto sob o ponto de vista do corpo genético quanto social. O problema, a nosso ver, é que a sociedade cria diferenças onde há igualdade e força a igualdade onde é preciso ver as diferenças. Acreditamos que homem e mulher deveriam ser vistos de maneira muito mais próxima, corporal e socialmente, do que o são no contexto atual. E ainda que encontremos muitas explicações históricas para os distanciamentos, não vemos razões que justifiquem a permanência, em pleno século XXI, de tantas disparidades.

Nesse sentido, consideramos importante desenvolver algumas reflexões sobre a forma como a escola tem lidado com as concepções de gênero e corporeidade e em que medida a maneira como as pessoas abordam estes temas repercutem socialmente.

\section{Escola, Concepções de Gênero e Corporeidade e Violência}

Quando tratamos das questões de gênero e sua relação com a concepção de corpo, especialmente no processo de formação de crianças e de jovens, cada ação educativa pode gerar uma ação/reação e deixar marcas profundas e imensuráveis. Nos relatos dos professores e das professoras com os quais trabalhamos, tivemos a oportunidade de observar que a própria constituição da vida, por vezes, trazia à tona questões indefinidas das relações com pais e/ou mães ou professores e/ou professoras em sua infância e adolescência, que demonstravam a dificuldade de abordar temas referentes ao ser homem e ao ser mulher na contemporaneidade. Por vezes, expressões sutis e até ditas sem

Roseli Alves Santos, Luiz César Teixeira dos Santos 
maior compreensão podem inibir manifestações corporais e provocar retraimentos, insatisfações que acompanham meninos e meninas por sua vida, sendo que estes podem, no futuro, se transformar em pais, mães, educadores e educadoras que repassam e reconstituem trajetórias marcadas em seus corpos, em suas vidas.

As atividades, envolvendo a corporeidade, trabalhadas pelos profissionais da Educação, especialmente na perspectiva da educação física, como destaca (ZUZZI e KNIJNIK, 2010), traz consigo a ideia marcada pelo higienismo e o militarismo. São atividades nas quais é bastante comum a separação entre meninos e meninas e pautados por prismas diferentes de que cada sexo tem suas atividades mais apropriadas, o que, segundo os autores, tende a fortalecer as desigualdades construídas historicamente.

Durante a realização das oficinas, os professores e professoras relatam que, mesmo a maior parte das atividades nas escolas sendo executadas de forma coletiva por meninos e meninas, as performances esperadas não são as mesmas, pois resultam da diferença sexual, o que é considerado como um resultado natural.

As distinções entre os sexos masculino e feminino (oficialmente reconhecidos no âmbito escolar) e a naturalização das diferenças nos remete à concepção de gênero trabalhada por Scott (1995), que possibilita compreender as diferenças por um prisma social e não como fruto de uma questão biológica.

Com base nas proposições da autora, a concepção de gênero que estamos tratando é aquela que se refere às relações sociais estabelecidas entre homens e mulheres, mulheres e mulheres, homens e homens. Relações estas que criam tratamentos desiguais e expressam formas de poder e dominação de uns sobre os outros, construídos a partir de pressupostos efetivados pela sociedade. A compreensão dos valores que fundamentam socialmente o ser homem e o ser mulher é que possibilita as formas de resistência ou manutenção dos processos de exploração e dominação decorrentes das relações de gênero desequilibradas e preconceituosas.

Vivemos um momento de retrocesso explícito no que se refere ao debate das questões de gênero nos contextos escolares, bem como um aumento da violência. A esfera legal tem sido utilizada como forma de proibir o debate de gênero nas escolas brasileiras. Projetos de lei, aprovados nas esferas municipais, tendem a coibir o debate de gênero sobre alegações de que os temas abordados resultam no incentivo à homosexualidade, à práticas sexuais precoces. O discurso presente nas diferentes esferas da sociedade, balizados por segmentos conservadores das igrejas, especialmente as cristãs, ecoam como determinante para coibir que temas como diversidade sexual, sexualidade e violência de gênero sejam discutidos nos espaços escolares. $\mathrm{O}$ discurso é sustentado como sendo esta uma tarefa exclusiva da família (tradicional, constituída pelo pai, mãe e filhos).

A contemporaneidade exige, ao contrário da legalização da proibição do debate de gênero e sexualidade nos espaços escolares, que o processo educativo formal, efetivado nas escolas, contribua para revitalizar e redimensionar as relações de gênero na qual estamos o tempo todo envolvidos, seja no âmbito doméstico, no trabalho, ou na vida social e política. Estas relações ainda têm na mulher uma ação subjugada e no homem um reforço das

Roseli Alves Santos, Luiz César Teixeira dos Santos 
ações violentas que, em função dos padrões engessados, faz com que a homofobia ganhe proporções lastimáveis. Nesse sentido, poderíamos perguntar: qual o envolvimento da escola com estas questões? Por acaso a escola ensina ou estima a homofobia? Incentiva que cresça a violência contra a mulher? As experiências relatadas por grupos de estudantes e docentes nos indicam que sim. Não de uma forma aberta e explícita, mas nas sutilezas e omissão ao deixar de lado tais questões por considerarem que elas não estão relacionadas aos conteúdos pedagógicos que devem e merecem ser ministrados. Mas quem apreende estes conteúdos na escola? A quais conteúdos nos referimos?

Nas relações concretas que estão envolvidos professores, professoras, alunas e alunos é comum ouvirmos que as letras das meninas são mais bonitas e delicadas, assim como elas. Logo, não causa estranheza um menino escrever com uma caligrafia ilegível, mas causa estranheza a delicadeza do mesmo. Afinal, na visão de senso comum homem não chora, afinal, o choro é coisa de mulherzinha (no diminutivo). Estamos nos referindo às representações corporais de gênero e que são utilizadas como justificativas para sucessos e fracassos, violências e repressões, enfim, estereótipos múltiplos. Isso sem falarmos no processo de naturalização das questões e diferenças de gênero, assim como as de classe e étnicas. Dessa forma, observamos que o processo pedagógico desenvolvido pela escola acaba por reafirmar que não se trata de algo passível de mudança e sim de aceitação e de adequação aos padrões normalmente estabelecidos. São representações de dominação e subjugação arraigadas em nosso cotidiano.

A forma como a sociedade tem lidado, historicamente, com as questões relativas à corporeidade, faz com que haja uma negação do corpo. Esta negação afeta a todos, a partir do nascimento, e vai se acentuando na medida em que passamos pelo processo de socialização efetivado pelos mais variados meios, tais como nas relações familiares, no clube, nas rodas de amigos, nas igrejas, no convívio social, na escola, enfim, em todos os ambientes onde travamos interações sociais. A negação corporal a que mencionamos se refere ao fato de termos que nos adequar aos padrões e clichês socialmente aceitos. Não se pode ser simplesmente do jeito que queremos, mas temos que ser conforme a sociedade deseja que sejamos. Por isso se institui, na maioria das vezes de modo imperceptível, um determinado padrão a ser seguido, determinado modelo de beleza, de comportamento socialmente aceito e desejável para o que se espera de um homem ou de uma mulher. É desejável para um menino que este se enquadre e se transforme, gradativamente, em um indivíduo viril, forte, que demonstra pouca sensibilidade a 'flor da pele', com certo ar dominador e embrutecido, assumindo papel central e determinante na relação entre homem e mulher, pois é assim que se espera que um 'macho' da espécie humana se comporte. Para a menina, busca-se transformá-la no estereótipo de Cinderela, meiga, sensível, frágil, sedutora, assumindo papel social subalterno, uma vez que é este, em maior ou menor medida, aquilo que a sociedade espera de uma mulher. Nesse sentido, a mulher é duplamente vitimizada, uma vez que além de sofrer com o processo de repressão social existente sobre o corpo, de um modo geral, também é discriminada e inferiorizada na relação com o homem.

Roseli Alves Santos, Luiz César Teixeira dos Santos 
Não é simples coincidência estatística que a violência contra a mulher seja muito maior que em relação aos homens. Ao nosso ver, esse fato ocorre porque a sociedade do século XXI continua extremamente atrasada do ponto de vista de assegurar avanços reais em relação à igualdade de gênero. A impunidade é absurdamente alta e, de certa maneira, há uma legitimação histórico-social para esta impunidade, à medida em que a sociedade, implicitamente, aceita como natural valores que contribuem para os preconceitos de gênero.

Atitudes que no dia a dia parecem banais e sem grandes implicações, demonstram um lastro bastante grande, como se a ação em si fosse apenas uma ponta de um iceberg que, abaixo ou por trás, sustenta uma gama de gestos e ações que estão carregados de valores. Como exemplo do que estamos falando, podemos citar alguns atos aparentemente sem importância, muitas vezes vistos como até 'engraçadinhos' e, o que talvez seja ainda mais preocupante, reforçados também pelas mulheres; é o caso do pai ou da mãe que leva o filho (menino) para fazer xixi em local público, mas não admite o mesmo para a filha. Por que a menina tem que ir ao banheiro e o menino pode fazer xixi em qualquer lugar? É só as características da genitália que explicam estas diferenças de atitude por parte dos progenitores? Pensamos que não! As nossas experiências como docentes e estudos de autores como Scott (1995), Louro (1997), Sayão (2002), entre outros, reforçam nosso entendimento de que as razões para tal diferença se explicam por questões sócio-históricas de como se construiu, ao longo do tempo, os papéis assumidos por homens e mulheres na sociedade.

De acordo com Sayão (2003), na sociedade patriarcal a demarcação e prevalência do poder masculino sobre o feminino remete as mulheres aos espaços privados e de circulação restrita, enquanto os homens são relacionados aos espaços públicos, de maior visibilidade. Esta premissa cria o estereótipo do corpo da mulher como privado, enquanto o corpo do homem é público. Isso explica também algumas piadas que se escuta, como aquela que diz, em relação à genitália masculina, que o bicho tem que ser criado solto. Para a mulher, desde quando ainda menina, é comum se dizer para sentar direito, com as pernas fechadas para não mostrar as coisas feias. Entre ser criado solto e aprender a controlar seus gestos e posturas de modo a não mostrar o corpo, mantendo-se sempre com uma conduta irrepreensível, podemos ver bem as diferenças e os papéis outorgados para o ser homem e o ser mulher.

Outra questão central atrelada à concepção de gênero e a lógica patriarcal (relacionado especialmente a dominação masculina), segundo Safiotti (2004), é a demarcação social do espaço privado e público, compreendido pela sociedade patriarcal como o espaço da mulher e do homem respectivamente.

$\mathrm{O}$ corpo segue a mesma lógica espacial destinada às relações de gênero, pois o corpo da mulher é compreendido como algo privado, em especial pertencente à figura masculina do pai, irmão, marido, cunhado; enquanto o corpo do homem é público, portanto ele pode e deve experimentá-lo de múltiplas formas. Se não o faz, também é acometido de estranheza, pois não segue o seu 'curso natural'. Mais uma vez a negação dos corpos que fogem a este padrão faz com que estes sujeitos sejam invisibilizados ou discriminados. Paradoxalmente, observamos uma exacerbada exposição do corpo feminino na mídia, que contradiz ao profundo controle social sobre o mesmo. O corpo 
masculino, ao contrário, não tem a mesma visibilidade, porém, tem um nível bem maior de liberdade. A representação da subordinação e da subjugação se manifesta concretamente, como podemos observar em um relato de uma senhora agricultora:

Antes as mulheres não pagavam ingresso e era só o rapaz que ganhava dinheiro dos pais para ir às festas, por isso as mulheres que entravam tinham que dançar com qualquer um que a convidasse, pois os homens estavam pagando ingresso: não podia dar carão, além de tudo a moça apenas ia ao baile se o irmão fosse, ela não tinha independência de sair (Agricultora, entrevista concedida em 2010).

As mulheres que não aceitam estas e outras formas de submissão são tachadas de subversivas ou, como destaca Joffly (2010), são associadas, como no caso das militantes políticas, pelos seus torturadores, como puta, vaca, vadia, contrastando com a visão geral que associa a figura da mulher às afeições familiares da mãe, da esposa, da filha ou irmã. Também os homens podem ir de garanhões (elogio) a florzinha (xingamento), dependendo da relação de poder e dominação que ele exerça socialmente no que se refere às questões de gênero.

O aspecto biológico do corpo é utilizado para legitimar as relações de gênero e as associações decorrentes. Como demonstra Joffly (2010), a maternidade pode representar, para as mulheres que se enquadram nos padrões de normalidade política, social e cultural, sinônimo de doçura e magnificência, enquanto para as que se desviam deste padrão a maternidade poderá ser associada à promiscuidade, à ilegalidade.

Você é gelada, insensível, que espécie de mulher é você? [...] entendi porque você é fria, você é chefe e não quer aparentar fraqueza diante de suas comandadas, mas eu sei que, por dentro, você é mulher, sensível, frágil. Li suas poesias e cartas ao seu marido, vi que você é bem feminina (JOFFLY, 1992, apud JOFFLY, 2010, p. 231).

Segundo Costa (2016), estas questões surgem no cotidiano escolar de forma hierarquizada como resultado das relações de poder, sendo esta definidora das formas e dos comportamentos dos atores escolares. De acordo com Costa (2016), a ratificação do binário homem/mulher se constitui numa análise fragmentada da sociedade e do espaço escolar. A visão binária e hierárquica dos corpos é um mecanismo de dominação e controle que serve "(...) para disciplinar, alienar e particularizar os corpos" (COSTA, 2016, p. 210).

A partir do momento que pensamos criticamente a produção discursiva destas normas organizadas de forma binária, tornamos instáveis suas realizações e liberamos diferentes formas de identificações de gênero e produção de sexualidades de diferentes contextos sociais que estão sendo classificados como minorias (COSTA, 2016, p. 209).

Roseli Alves Santos, Luiz César Teixeira dos Santos 
Durante a realização das oficinas, verificamos que nos espaços escolares são reveladas relações de preconceitos elaborados em torno do discurso de gênero. Exemplo desta problemática pode ser percebido em uma frase costumeiramente dita para as meninas que têm atitudes mais agitadas e/ou agressivas: você quer se igualar aos meninos? Se tomarmos como normal e considerarmos que meninos podem ser agressivos/agitados sem ser amplamente questionados, que meninos podem e devem ter novas experiências, que meninos obtêm respeito proporcionalmente a sua agressividade, que meninos não precisam dedicar-se horas a caprichar sua caligrafia, entre outras questões, as expressões e frases que, a princípio, são repreensões ou formas de xingamento se tornam, efetivamente, um prêmio.

A pergunta acima revela em si uma ambigüidade e fomenta o lugar daquele que pode e aquela que não pode em decorrência de ter uma genitália diferente. Questões como essa, quando não compreendidas e discutidas no ambiente escolar, fomentam o distanciamento entre os sexos e uma distinção que provoca preconceitos geradores de violência dentro e fora da escola. Neste caso, ser comparada com um menino é uma forma de humilhação. O contrário também é verdadeiro e meninos sofrem escondendo seus sentimentos para não serem comparados à delicadeza feminina.

Ao tratar de violência, corpo e escolarização, Oliveira (2006) nos dá exemplos de como as relações de gênero estão disseminadas nos espaços do recreio escolar e passam, na maior parte das vezes, despercebidas pelos educadores, deixando de ser utilizadas como uma importante ferramenta pedagógica no rol das disciplinas escolares, o que para a autora se constitui em um grande erro. Os elementos formativos ou deformativos estão, por exemplo, na forma como os espaços são compartilhados, pois, geralmente os melhores e mais procurados espaços da escola são ocupados pelos mais fortes.

Além disso, no momento do recreio também ficam evidentes as práticas moralmente aceitas para cada sexo, isto é, as atitudes esperadas de uma menina e de um menino. Caso alguma convenção seja rompida, ela acaba sendo rapidamente identificada pelo grupo, que de pronto relaciona isso com algo anormal e estabelece juízos preconceituosos sobre essas condutas (como exemplos: a menina que joga futebol com os meninos ou o menino que brinca com as meninas). Assim os tabus entre gênero são perpetuados, sem serem questionados ou, ao menos, problematizados pelos professores que, na maioria das vezes, negligenciam essas circunstâncias (OLIVEIRA, 2006, p. 65-66).

Estes preconceitos, gerados por uma sociedade de domínio patriarcal, negam o autoconhecimento, especialmente às mulheres. Como exemplo, a masturbação é tida por muitos educadores como uma fase pela qual passam os meninos (natural é evidente), já as meninas crescem com o estigma de um corpo inviolável (até mesmo pelas suas próprias mãos). Qualquer oposição aos modelos estabelecidos é passível de punição, seja pela escola ou pela família, pois é tido como uma afronta à sociedade. São padrões sociais que devem ser

Roseli Alves Santos, Luiz César Teixeira dos Santos 
seguidos e respeitados e seus infratores punidos, mesmo quando a lei dispõe do contrário.

Por vezes, as questões de gênero, assim como de sexualidade, aparecem no contexto escolar em uma relação de penosidade subjetiva, que induz as crianças a se sentirem culpadas pela descoberta do próprio corpo. São ações de pais, professores e professoras que na tentativa de inibir ações que não dominam utilizam jargões do tipo: como isso é feio; isso não se faz; você vai para o inferno; entre outras falas que não contribuem para que crianças e adolescentes compreendam a sua sexualidade. Essas questões são acompanhadas de um julgamento de valor diferenciado entre meninos e meninas. Sobre as meninas o peso moral é sempre maior, pois são definidas como frágeis e dominadas. Estamos falando dos papéis definidos e reafirmados pela sociedade em suas práticas cotidianas, que reforçam a discriminação e o preconceito.

O preconceito gerador da violência, embora seja criado pelo dominante, neste caso a sociedade patriarcal, é reforçado por todos, dominantes e dominados, homens, mulheres, independente da diversidade sexual existente. Por isso este debate na escola ganha uma dimensão fundamental, pois as crianças e jovens são seres em formação biológica, política, econômica, cultural que podem fazer leituras diferenciadas das relações de gênero e da corporeidade.

A escola, assim, torna-se um território por excelência de reprodução de uma linguagem que polariza e hierarquiza os gêneros e as sexualidades, constituindo normas discursivas reproduzidas de modelos que preservam as formas hegemônicas de representação do masculino e da heterossexualidade compulsória. A reprodução hegemônica de discursos imaginários sobre os atributos, as estéticas e as formas de comportamento sobre os gêneros e sobre as sexualidades separam-se radicalmente da diversidade de possibilidades de representações e manipulações simbólicas diversas trazidas pelos sujeitos todos que se encontram na escola. Ocorre um abafamento institucional que cria um espaço discursivo e simbólico que escapa e reprime as coisas mesmas, ou seja, a realidade diversa dos sujeitos escolares (COSTA, 2016, p. 211).

Ao tratar da escola como questionadora de um círculo homofônico, por exemplo, Facco (2011) demonstra que a negação do homoafetivo gera sujeitos considerados estigmatizados que ao serem forçados a esconder sua condição concreta de existência para serem aceitos na sociedade, por vezes, além do sofrimento decorrente do preconceito, acabam por estabelecer uma relação de proximidade muito forte com a violência. A autora traz exemplos de casos de violência em espaços coletivos como escola que, mais tarde, leva a tragédias como a ocorrida na escola em Realengo, na qual o jovem que matou alunos da escola e depois se suicidou teve um histórico de violência e perseguição naquele ambiente quando criança. Um processo de violência nem sempre relacionado à questão afetiva, mas vinculado à corporeidade e aos padrões a 
ela estabelecidos. Assim, aos estigmatizados e aos não estigmatizados cabe um enquadramento ao modelo social construído, o que efetivamente resulta em condições limites.

$\mathrm{Na}$ verdade, esse processo de desvendamento funciona como um círculo vicioso. A aceitação dos limites impostos está diretamente relacionada à culpa que o sujeito estigmatizado assimila e mantém dentro de si. A certeza de que 'está errado', ou pior, de que 'é anormal', faz com que ele se conforme com a necessidade de se ajustar a todo custo. O esforço do sujeito estigmatizado para se adaptar reforça, para o não estigmatizado, a 'certeza' de que o estigma faz o seu portador um indivíduo 'inferior'. Daí, maior será o reforço da culpa para o estigmatizado, e assim por diante, ad aeternum.

O ciclo precisa ser quebrado, tarefa que caberá ao estigmatizado. A escola deveria ser uma instituição de grande valia para realizar o difícil e lento processo de questionamento dos padrões castradores de comportamento, imagem, afetividade (FACCO, 2011, p. 25).

É nesta perspectiva de construção e desconstrução que os debates entre os grupos educadores devem ocorrer e não na lógica da punição para que não seja, equivocadamente, compreendido como uma forma de desvio de conduta, escondendo o caráter social simbólico e material que a violência expressa.

$\mathrm{O}$ apego às questões legais é outra atitude que tem servido de subterfúgio para não se conhecer e discutir as diferentes formas de preconceito decorrentes das questões de gênero. Ela é utilizada em um discurso resolutivo, como é o caso da Lei Maria da Penha, Lei contra homofobia que, entre outras, proíbem formas de violência decorrentes das relações de gênero, mas não as coíbe, pois este é um tema encerrado, uma vez que essas ações consistem em crime e já existem leis para puní-las.

Em termos de legislação, apesar dos retrocessos verificados com ameaças de exclusão das questões ou mesmo sua efetivação nas formulações dos Planos Municipais de Educação em 2015, o Brasil apresenta um escopo legal avançado, no reconhecimento de direitos, por exemplo, no que se refere ao casamento de pessoas do mesmo sexo. Mas, contraditoriamente, tais sujeitos têm negado seu reconhecimento em muitos espaços sociais. No mesmo sentido, encontra-se a legislação existente sobre a violência contra mulheres e o aumento crescente desta forma de violência.

Desta forma, é crescente no país o aumento da violência praticada contra mulheres e homoafetivos, indicando, sem negar a importância da lei, à sua ineficiência, pois essas são geradas em um contexto de preconceito e é este que deve ser amplamente debatido, visibilizado e embargado.

Segundo relatório divulgado pela Secretaria Nacional de Direitos Humanos, o Brasil tem avançado no sentido de colocar em debate público a questão da população de transexuais, travestis, lésbicas, bisexuais, e gays - LGBT, sendo o próprio relatório considerado como um instrumento de avanço por dar visibilidade à violência vivenciada. Mas é fundamental destacar que os números por si não desmontam uma estrutura patriarcal rígida e homofóbica de 
uma cultura heteronormativa, são necessárias ações efetivas e educativas.

No entanto, a superação da sociedade patriarcal e da heteronormativa é uma condição à construção de um efetivo respeito à dignidade e aos direitos humanos. A transformação de tais padrões estigmatizados não é algo rápido e nem de fácil realização, pois requer a desconstrução e reconstrução de valores. Nesse aspecto, considerando a expressiva violência decorrente da orientação sexual e da identidade de gênero, somando ainda as questões étnicas e de pobreza, toda manifestação contrária às diferentes expressões de discriminação geradora de violência são fundamentais.

Discriminações são violências cometidas contra indivíduos por motivos diversos, possuem um forte componente de violência simbólica, e podem ser exercidas também pelo poder das palavras que negam, oprimem ou destroem psicologicamente o outro. Nesse sentido, é notável o poder do preconceito sofrido, que infere não apenas na conformação das identidades individuais, mas também no delineamento de possibilidades de existência e trajetória de vida da população LGBT na sociedade brasileira. Vale também sublinhar que a violência homofóbica é cometida contra os indivíduos cuja orientação e/ou identidade de gênero presumidas não se conformam à heteronormatividade. Ou seja, são também recorrentes episódios contra sujeitos que, apesar de se autoidentificarem como heterossexuais, têm a eles atribuídas características que fazem com que os perpetradores das violências os classifiquem como LGBT (BRASIL, 2012, p. 11).

Neste contexto de violência homofóbica, a exclusão da temática no contexto escolar é a contribuição para o aumento da violência e as ações das educadoras e dos educadores podem potencializar a mesma, através do reforço aos padrões heteronormativos. Assim, o conhecimento e o reconhecimento são importantes instrumentos para o planejamento e a execução de mudanças, que devem ser processadas no cotidiano, assim como nas esferas públicas de poder, dentre elas a Escola, mas não somente.

E ainda, a escola acaba por resultar em um ambiente hostil com consequências físicas, emocionais e para o desenvolvimento das pessoas LGBT. Por exemplo, o bullying, injúria ou assédio, físicos ou verbais, estudantes frequentam menos as aulas, abandonam a escola, passam por problemas de sociabilidade e de relacionamento com 'o outro', podem tornar-se mais vulneráveis às drogas e até mesmo ao suicídio. Além disso, o heterossexismo reforça o sexismo por promover padrões rígidos de gênero (DANILIAUSKAS 2010, p. 27).

Reafirmamos que, nesse contexto, as crianças e jovens são os que estão mais suscetíveis à violência decorrente da homofobia, por exemplo. Os dados referentes à idade das pessoas que sofreram violência homofóbica no Brasil, 
em 2012, reforçam a necessidade da implantação de um processo educativo, pois $61,16 \%$ eram jovens entre 15 e 29 anos, seguidos dos $17,45 \%$ na faixa etária entre 30 a 39 anos (conforme gráfico a seguir).

Gráfico 01: Faixa etária das vítimas de violência homofóbica 2012

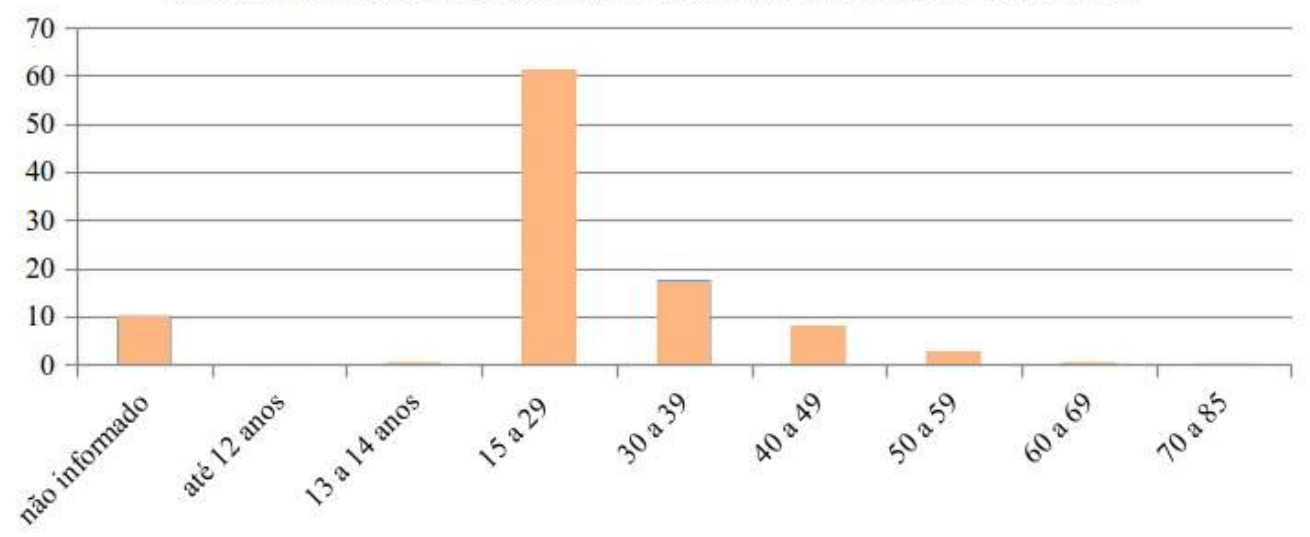

Fonte: Relatório sobre violência homofóbica no Brasil: ano 2012.

O mesmo relatório indica ainda que, em referência ao agressor(a), as faixas etárias predominantes são entre 15 a 29 anos $(27,7 \%)$ e 30 a 39 anos $(16,85 \%)$, sendo que as demais seguem a mesma proporção daquela apresentada no gráfico 01 .

No que se refere à relação entre o agressor e a vítima de violência homofóbica o destaque é dado a desconhecidos (29,54\%), seguido de vizinho(a) com $20,69 \%$ e da família com 20,44\%. Outros, como excompanheiro, professor, empregador, etc., representam $9,89 \%$ e aqueles que não se aplica a nenhuma destas situações configuram 6,06\% dos casos. A proximidade com a vítima ganha destaque, seja pela relação de parentesco ou por vizinhança, expressando certa forma de domínio sobre o outro na forma de violência, com o intuito, por vezes, de modificar a orientação sexual e a identidade de gênero do outro. As manifestações de violência homofônicas ocorrem na maioria dos casos (38\%) na própria casa da vítima, tendo como principal expressão a discriminação, a violência física, a violência psicológica e a sexual.

Em 2012, foram divulgadas nos principais canais midiáticos brasileiros 511 violações contra a população LGBT, envolvendo 511 vítimas e 474 suspeitos. Entre as violações noticiadas encontram-se 310 homicídios (BRASIL, 2012, p. 39).

Com base nos dados e nos relatos verificados durante a realização das oficinas, reafirmamos que o conhecimento e o reconhecimento da diversidade sexual e da compreensão do caráter social das relações de gênero são fundamentais para a emancipação dos sujeitos, independente de sua orientação sexual ou identidade de gênero. A concepção teórica, neste caso, deve estar acompanhada de uma prática que envolve uma relação dinâmica e de movimento, de desconstrução e (re)construções simultâneas e paralelas. Assim, tratar de questões de gênero e corporeidade é tratar de questões de movimento social, não somente o feminista organizado, que tem contribuído na emancipação das mulheres, mas também o movimento cotidiano. 
Tabela 01- Violência Homofóbica no Brasil.

\begin{tabular}{|c|c|c|}
\hline & 2011 & 2012 \\
\hline Denúncias & 1.159 & 3.084 \\
\hline Violações & 6.809 & 9.982 \\
\hline Vítimas & 1.713 & 4.851 \\
\hline Suspeitos & 2.275 & 4.784 \\
\hline
\end{tabular}

Fonte: Relatório sobre violência homofóbica no Brasil: ano 2012.

Os dados da tabela 01 demonstram o aumento da violência homofóbica em um ritmo mais acentuado. O número de vítimas aumentou $283 \%$ no período, enquanto a denúncia aumentou $266 \%$. Os dados demonstram que o Brasil tem se dedicado à questão, embora de forma tênue. Não basta estar na pauta de discussões, é preciso intensificar o debate e a efetivação de ações, entre elas as de âmbito educativo.

\section{Considerações Finais}

Uma leitura multidisciplinar da importância da educação e compreensão do processo educativo da corporeidade, relacionado às construções sociais sobre o conceito de gênero mostrou ainda haver, de modo bastante forte entre educadoras, um histórico de entendimento e práticas reforçadoras de estereótipos de gênero.

A maneira de ser e viver o 'ser homem' ou o ser e viver o 'ser mulher' está mediado pela cultura dominante da época que vivemos. Período este que construiu modelos e papéis do que presumivelmente deva ser o masculino e o feminino em nossa sociedade. O problema de um modelo que prevê comportamentos de fora para dentro é o fato de negar à pessoa a liberdade de escolha, ou ainda, de sujeitar as escolhas àquilo que é socialmente aceitável como parâmetro de normalidade. Afinal de contas, o que é ser normal? Por que fazer algo diferente do que todo mundo faz é visto como um problema para a sociedade e para a escola? Existe algum problema em um homem ser delicado e uma mulher ser rude e áspera? Se existe problema onde ele está?

A violência ligada às questões de gênero parecem estar vinculadas à intolerância que há em relação às pessoas que simplesmente são diferentes do padrão heteronormativo estabelecido. Ainda que o brasileiro se veja como um povo acolhedor e liberal, com base no que observamos durante os eventos nos quais debatemos sobre a questão da mulher na sociedade contemporânea e as implicações oriundas da conformação do conceito de gênero em nossa sociedade, é possível afirmar que a realidade expõe duramente esta visão falsa e romantizada do povo brasileiro. Em se tratando de gênero, a violência declarada, aquela que aparece nos noticiários ou que é registrada nas delegacias, é uma fração minúscula do todo, pois há a violência tácita, que não se dá a conhecer de maneira espontânea e, na maioria das vezes, nem é 
percebida como um ato de violência de gênero ou, no mínimo, como formas de preconceito que, se não são explicita ou concretamente violentas, como piadas e tratamentos desiguais entre meninos e meninas, são formas que reforçam estereótipos de gênero e, portanto, em maior ou menor grau, acabam reforçando e sendo complacentes com o que ocorre socialmente.

Os relatos apresentados durante as oficinas formativas nos indicam que os preconceitos de gênero, assim como a pouca compreensão e respeito sobre o corpo, estão fortemente presentes no contexto da sociedade brasileira, não apenas entre os cidadãos de um modo geral, mas também no seio da escola, entre professores, professoras e estudantes.

\section{Referências}

BRASIL. Secretaria de Direitos Humanos. Relatório sobre violência homofóbica no Brasil: ano 2012. Brasília, 2012.

CAMURÇA, Sílvia; GOUVEIA, Taciana. O que é gênero. Recife: SOS CORPO - Instituto Feminista para a Democracia, 2004. 40p. - (Cadernos SOS CORPO; v.1).

COSTA, Benhur Pinós. A escola como espaço: identidade de gêneros e sexualidades e suas hierarquias. Revista da Associação Nacional de Pósgraduação e Pesquisa em Geografia, v. 12, n. 19, p. 204 - 225, 2016.

DANILIAUSKAS, Marcelo. Relações de gênero, diversidade sexual e políticas públicas de educação: uma análise do Programa Brasil Sem Homofobia. 2010. Dissertação (Mestrado em Educação) - Universidade de São Paulo, São Paulo.

FACCO, Lucia. A escola como questionadora de um currículo homofóbico. In: SILVA, Joseli Maria; SILVA, Augusto Cesar Pinheiro da. Espaço, gênero e poder. Conectando fronteiras. Ponta Grossa: Toda Palavra, 2011, p. 19 - 30.

GAIARSA, José Ângelo. O que é corpo. São Paulo: Brasiliense, 1986.

JOFFLY, Olivia Rangel. O corpo como campo de batalha. In: PEDRO, Joana Maria; WOLFF, Cristina Scheibe. Gênero, Feminismo e Ditadura no CONESUL. Florianópolis, 2010, p. 225 - 245.

JUNQUEIRA, Rogério Diniz (Org.). Diversidade Sexual na Educação: problematizações sobre a homofobia nas escolas. Brasília: Ministério da Educação, Secretaria de Educação Continuada, Alfabetização e Diversidade, UNESCO, 2009.

LOURO, Guacira. Gênero e magistério: identidade, história e representação. In: CATTANI, Denise et al. (Org.). Docência, memória e gênero. Estudos sobre formação. São Paulo: Escrituras, 1997.

OLIVEIRA, Luciane Paiva Alves de. Violência, Corpo e Escolarização: 
apontamentos a partir da teoria crítica da sociedade. In: OLIVEIRA, Marcus Aurélio Taborda de (Org.). Educação do Corpo na Escola Brasileira. Campinas: Autores Associados, 2006, p. 57 - 70.

SAFIOTTI, Heleieth. Gênero, patriarcado, violência. São Paulo: Fundação Perseu Abramo, 2004.

SAYÃO, Deborah Thomé. A construção de identidades e papéis de gênero na infância: articulando temas para pensar o trabalho pedagógico da Educação Física na Educação Infantil. Revista à Prática, v.5, p.1 - 14, 2002.

SAYÃO, Deborah Thomé. Corpo, poder e dominação: um diálogo com Michelle Perrot e Pierre Bourdieu. Perspectiva. v. 21, n. 1, p. 121 - 149, 2003.

SCOTT, Joan. Gênero: Uma categoria útil de análise histórica. Educação e Realidade, v. 20, n. 2, p. 71 - 99, 1995.

SILVA, Joseli Maria. ORNAT, Márcio Jose. Corporeidade: sexualidades no mercado sexual transnacional sob o olhar eurocêntrico. GEOUSP: espaço e tempo, v. 20, p. 69 - 82, 2016.

SILVA, Susana Maria Veleda da. Os estudos de gênero no Brasil: algumas considerações. Revista Bibliográfica de Geografía y Ciencias Sociales, n. 262, 2000.2 Disponível em:< http://www.raco.cat/index.php/Biblio3w/article/view/65695>. Acesso em $10 \mathrm{de}$ Junho de 2017.

ZUZZI, Renata Pascoti; KNIJNIK, Jorge Dorfman. Do passado ao presente: reflexões sobre a história da educação física a partir das relações de gênero. In: KNIJNIK, Jorge Dorfman; ZUZZI, Renata Pascoti. Meninas e Meninos na Educação Física: Gênero e Corporeidade no Século XXI. Judiaí: Fontoura Editora Ltda, 2010, p. 59 - 70. 